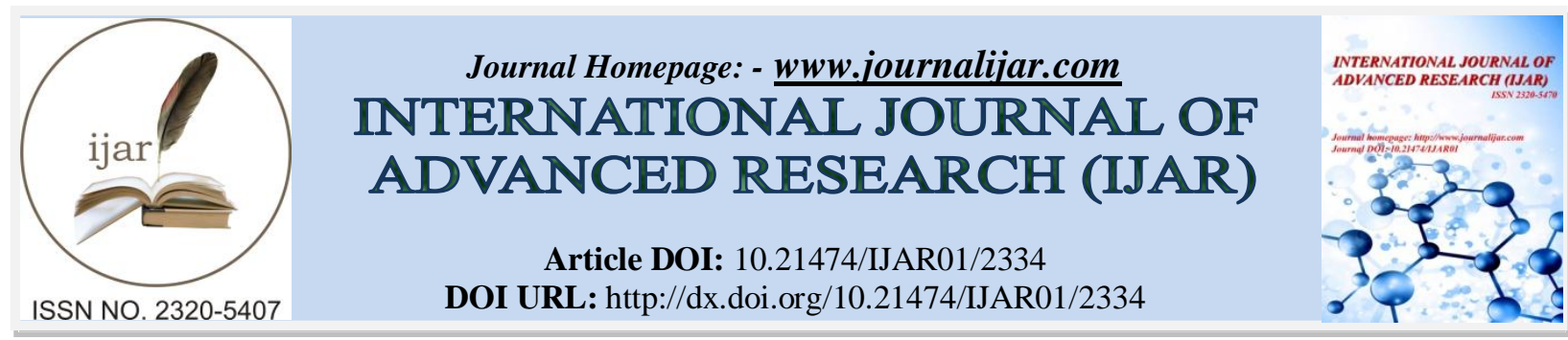

RESEARCH ARTICLE

\title{
KNOWLEDGE, ATTITUDE AND PRACTICES TOWARDS OSTEOPOROSIS AMONG SAUDI POPULATION IN TAIF CITY.
}

\author{
Rania Mohammed Ahmed ${ }^{1}$, Dalal Al Harthi ${ }^{1}$, Azhar Algithami ${ }^{1}$, Reem Alroqi ${ }^{1}$, Sultan Alamri ${ }^{1}$ and Abdul \\ Rahman Al Oufi'. \\ 1. Radiology Department, College of Applied Medical Sciences, Taif University P.O.Box2425, post code 21944 , \\ Taif ,Saudi Arabia. \\ 2. Radiology Department, King AbdulAziz Specialist Hospital, Taif, Saudi Arabia.
}

\section{Manuscript Info}

[.........................

Manuscript History

Received: 30 September 2016

Final Accepted: 30 October 2016

Published: November 2016

Key words:-

Osteoporosis, Knowledge, Attitude,

Female, Age, Bone mass density

(BMD).

\section{Abstract}

Osteoporosis remains a major global public health concern. In Saudi Arabia osteoporosis is a serious issue, with the kingdom's population of 1,461,401 aged 50 or more, approximately 8,768 suffer from femoral fractures each years, costing yearly 1.14 billion in health care cost .In women over 45 years of age osteoporosis accounts for more days spent in hospital than many other diseases, including diabetes and breast cancer .Aim of the study :To assess knowledge, attitude and practices towards osteoporosis, also to find out most common risk factors among population in Taif city. Method:Cross sectional descriptive study was conducted at King Abdul Aziz Specialist Hospital and King Faisal Hospital, Taif city, KSA in a sample of 109 patients in the period from Jan to April 2016. Result :25 patients (22\%) were diagnosed with osteoporosis, 52 patients (48\%) with osteopenia and 30 patients (28\%) were normal on BMD test, a significant correlation was found between age and BMD test $(\mathrm{P}=0.023)$, most affected age group with osteoporosis was (51 and above) with (74\%). Conclusion: Knowledge of osteoporosis among the study sample was moderate as regards its risk factors, but was very low about BMD test. (52.3\%) do exercises. (71\%) drink milk (45\%) take calcium dietary supplements. Only (19\%) eat enough amount of fruits everyday and only (2.8\%) smoke cigarettes. Awareness level should be elevated among Taif community to prevent further growth of osteoporosis.

\section{Introduction:-}

Osteoporosis, defined as an asymptomatic systemic bone disease is characterized by low bone mass and micro architectural deterioration of bone tissue, with a consequent increase in bone fragility and susceptibility to fracture (Khosla, et al ,2008). The World Health Organization defines osteoporosis as a bone density of 2.5 standard deviations or more below a reference group of young Caucasian females (World Health Organization, 2004). Osteoporosis should no longer be considered an old women's disease but rather young women should also be included (Karimi, ,2011).Individuals often don't even know they have the disease until a bone is broken in a minor

Corresponding Author:- Rania Mohammed Ahmed.

Address:- Radiology Department, College of Applied Medical Sciences, Taif University P.O.Box2425, post code 21944 , Taif ,Saudi Arabia. 
fall that wouldn't normally cause a fracture (Wellness works Magazien,2008) Primary osteoporosis affects women 6 times more than men. The most common type of primary osteoporosis is that caused by estrogen withdrawal either due to menopause, ovarian failure or bilateral oophorectomy (Genant, et al.1996).

Family history of fractures, personal history of fracture as an adult, cigarette smoking, alcohol drinking, thin build, use of oral gluco-corticosteroid therapy for 3 months or more or having history of rheumatoid arthritis, thyroid disease, liver disease as major risk factors for low Bone density (Maalouf, et al,2007, Rouzi, et al,2012) Other important risk factors include the hormonal role, degree of physical activity, calcium and vitamin D intake and drugs especially corticosteroids (Szule, et al,2002)

Diseases commonly associated with increased risk of developing generalized osteoporosis in adults include hypogonadal states, endocrine disorders such as Cushing's syndrome, hyperparathyroidism, thyrotoxicosis, insulindependent diabetes mellitus, a acromegaly, and adrenal insufficiency, nutritional and gastrointestinal disorders, rheumatologic disorders including rheumatoid arthritis and ankylosing spondylitis, hematologic disorders and malignancy such as multiple myeloma, lymphoma, leukemia, and malignancy-associated parathyroid hormonerelated production, several inherited disorders, and other disorders such as immobilization, chronic obstructive pulmonary disease, pregnancy and lactation, scoliosis, multiple sclerosis, sarcoidosis, and amyloidosis ( Linwdsay, Cosman, 2001). Medications that may be associated with osteoporosis include glucocorticosteroids and adrenocorticotropins, gonadotropin-releasing hormone agonists, immunosuppressant's, cytotoxic drugs, anticonvulsants (Phenobarbital, phenytoin), aluminum, long-term heparin use, long acting parenteral progesterone, supraphysiologic throxine doses, tamoxifen, and total parenteral nutrition, of these, glucocorticosteroids are the most important and most commonly used.

Worldwide, osteoporosis causes more than 8.9 million fractures annually, resulting in an osteoporotic fracture every 3 seconds. (Johnell, et al.2006). For the year 2000, there were an estimated 9 million new osteoporotic fractures, of which 1.6 million were at the hip, 1.7 million were at the forearm and 1.4 million were clinical vertebral fractures. Europe and the Americas accounted for $(51 \%)$ of all these fractures, while most of the remainder occurred in the Western Pacific region and Southeast Asia (Johnell, et al,2006). In the USA, (16\%) of postmenopausal Caucasian women are estimated to have osteoporosis in the lumbar spine. In comparison, a higher prevalence was observed among Japanese women aged between 50 and 79 years (35\%) in the spine and (12\%) in the hip. Another study involving healthy postmenopausal women in Denmark indicated (50\%) prevalence of osteoporosis in those older than 50 years (Bener et al, 2007). In Australia 2 million Australians are affected by osteoporosis (Sambrook, et al, 2002) . Every 8.1 minutes in Australia someone is admitted to hospital with a fracture (Ego Seeman and John A Eisman,2004). In New Zealand, osteoporosis causes 15,000 fractures each year, of which around 3,000 are hip fractures (HRC, 2004) . Osteoporosis affects more than half of women, and nearly a third of men over age 60 (Damodsaran, et al,2000) . In Arabic word Hip fractures occur at a younger age in Lebanon compared to Western populations, and 60\% of patients with hip fractures have osteopenia rather than osteoporosis (Maalouf, et al,2006) In Qatar, the prevalence of osteoporosis among postmenopausal women was found to be( $12.3 \%)$, this result is similar to the study findings of Jordan where (13\%) of women aged 40-60 had osteoporosis. (Bener et al,2007) .

In Egypt Calculations show that $53.9 \%$ of postmenopausal women have osteopenia while $28.4 \%$ have osteoporosis (Mohy,,2011) (21.9\%) of males aged 20-89 have osteoporosis (MEARA,2011) It is estimated that there are about 15,000 vertebral fractures each year in Syria of which only (20\%) are treated by a doctor (MEARA,2011). In Saudi Arabia in the past decade osteoporosis has been looked at more as a curiosity than a problem, even though many studies have reported a high prevalence of osteoporosis among Saudi women (Sadat, et al,2004, Sadatet al,1996). It was documented that (24\%) of Saudi women had osteoporosis (Bener ,et al., 2007). In a study of 483 postmenopausal Saudi women aged 52 to 62 years, El-Desouki found the prevalence of osteopenia and osteoporosis to be (34\%) and (24\%),respectively (El-Dessouki,1999). According to osteoporosis foundation fact sheet, 1 in 3 women who are over 50 years will suffer a fracture due to osteoporosis and these increases to 1 in 2 who are over 60 years of age (Bener ,et al., 2007). Several previous studies found that the mean knowledge of osteoporosis was significantly higher among highly educated women (Kutsal et al ,2005, Saw et al ,2003). Bone mineral density test (BMD) is used in clinical medicine as an indirect indicator of osteoporosis and fracture risk. BMD is often used as an estimate measure for bone strength while it only accounts for (70\%) of bone strength (Karimi, et al. 2011). Proper diagnosis and management of osteoporosis minimize injury, disability and improves quality of life for patients and reduce costs to society (Rasy, et al,1997).The BMD diagnosis of normal, low bone mass (osteopenia), 
osteoporosis and severe or established osteoporosis is based on the WHO diagnostic classification score (SD), Normal (-1) and above Osteopenia(-1 to -2.5$)$ and Osteoporosis (<-2.5).

\section{Significance of The Research:-}

In Saudi Arabia osteoporosis is a serious issue, with the kingdom's population of 1,461,401 aged 50 or more, approximately 8,768 suffer from femoral fractures each years, costing yearly 1.14 billion in health care cost (Leslie and Morin, 2014). In women over 45 years of age osteoporosis accounts for more days spent in hospital than many other diseases, including diabetes, myocardial infarction and breast cancer (Kanis, 2007).So this study aimedto:

Assess knowledge, attitude and practices towards osteoporosis among Saudi population in Taif city, Find out most common risk factors among population in Taif city.

\section{Material and Methods:-}

Study Design:-

Cross sectional descriptive design was used in the conduction of this study.

\section{Study Setting:-}

The study was conducted at King Abdul Aziz Specialist Hospital (KAASH) and King Faisal Hospital (KFH), Taif city, KSA

\section{Sample size:-}

A total of 109 patients were interviewed for this study. Researchers interviewed subjects who visited one of the two hospitals to have a BMD examination and were willing to participate in the period from January to April 2016.

\section{Data collection tools:-}

A questionnaire designed by the researcher was used to collect study data and filled by the patients after their BMD screening test.The questionnaire consisted of four parts:

First part ,concerned with demographic characteristics of the patient as (age, gender and family history of osteoporosis ).

Second part, concerned with knowledge of the patient as (osteoporosis, BMD test and cortisone effect on bone health).

Third part,included life style of the patients, as (walking, patient diet (fruit and milk consumption), calcium supplement and cigarettes smoking)

Fourth part, included patients BMD test results.

\section{Methods of data collection included:-}

A written permission to carry out the study was obtained from the directors of each hospital to collect the necessary data after explanation the aim of present study. Interview by the prepared sheet to assess awareness, practice and attitude, each patient was interviewed individually and the questionnaires were filled by the researcher who was asking the patient $\&$ documenting their answer. The sheet was filled and completed in 25 minutes.

ii) Validation of tool was assessed before data collection, jury composed of 5 experts in radiology and nursing staff revised the content of validity to ascertain the appropriateness of items for measuring what they are supposed to measure.

iii) Tool reliability: the researchers applied it to a pilot study was conducted to evaluate the validity and reliability of the tool. It was carried out on 7 patients suffering from osteoporosis drawn from the previous settings. These patients were excluded from the actual sample. Also the pilot study was done to evaluate the applicability and clarity of the tool. Accordingly, the necessary modifications were done. The reliability test was calculated using correlation coefficient and it was 0.89 which is appropriate for conducting such a study. 


\section{Procedure protocol, patient preparation and position:-}

Login patient information on computer screen and enter patient weight and length on weight data entry screen. If the patient was in the anthropometry (BM) component or respiratory health $(\mathrm{RX})$ component prior to this test, the weight will already be uploaded and displayed on the ISIS screen, along with the component from which it transferred (i.e., BM, RX). If the information is not displayed, you will need to measure the patient weight using the floor scale in the room. The same precision to take the weight measurements in the anthropometry component must be used in this component, if the patient weight is more than 300 pounds, he or she will be excluded from the entire component due to weight limitation of the table. The technologist should briefly explain the examination when the patient is brought into the room; the exam should be explained in more detail as each scan is being completed. Have the patient remove all objects from his or her shirt and pants pockets (e.g., wallet, cell phones, underwire bras), False teeth, hearing aids, jewelry, and watches do not have to be removed. Make sure the patient is in the center of the table with respect to the center lines at the head and foot of the pad. Confirm that the patient is lying straight on the table. One method to check this is to position yourself at the foot of the table and look at the alignment of the body. Visualize a straight line from the nose, center of the body, and down through the knees and toes. Patient is either scanned in lumbar spine or hip joint.

AP Lumbar spine with beam collimated to include 1st to 4th lumbar vertebrae, patient lying down straight on the table , large square cushion was placed under patient legs with thighs as close to a $90 \%$ angle to the body.

AP one hip joint with beam collimated to include hip joint to proximal end of humorous. The hip scan positioning device was placed on the far left end of the table near the patient feet. Align the center of the device with the patient's midline. The leg to be examined should be rotated inward so that the foot can be placed against the positioning device and secured with the strap. The abduction of the leg was adjusted so that the shaft of the femur is parallel with the center of the table. The total procedures usually took about 5 to 10 minutes to finish depending on patient cooperation.

\section{Data Analysis:-}

Data was revised, coded, entered, analyzed and tabulated using IBM SPSS statistics 20.Both descriptive statistics (as means and standard deviation) and inferential statistics were used.

\section{Human rights and ethical considerations:-}

Ethical approval was obtained from ethic committee at King Abdul Aziz Specialist Hospital (KAASH) and King Faisal Hospital, also an oral consent was taken from each patient before data collection. Confidentiality and anonymity were assured. Study subjects have the right to refuse to participate or withdraw from the study at any time.

\section{Results:-}

Fig (1): Distribution of osteopenia and osteoporotic patients among study sample. (N=109)

\section{Fig.1. BMD test result among participant $\mathrm{N}=109$}

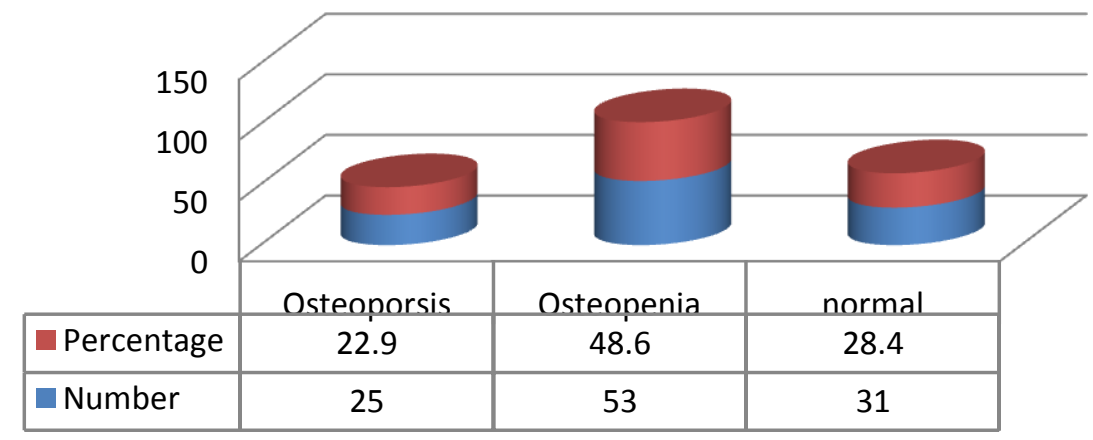

Fig 1:- Represented that (48.6\%) have had osteopenia, $(22.9 \%)$ osteoporosis and (28.4\%) were normal. 
Table 1:- Demographic characteristics of participants. ( $N=109)$

\begin{tabular}{|l|c|c|}
\hline Variables & No & \% \\
\hline Age \year & & \\
$20-30$ & 4 & 3.7 \\
$31-40$ & 11 & 10.1 \\
$41-50$ & 13 & 11.9 \\
51 -and above & 81 & 74.3 \\
\hline Gender & 100 & 91.7 \\
Female & 9 & 8.3 \\
Male & 94 & 86.2 \\
Marital status & 8 & 7.3 \\
Married & 7 & 6.4 \\
Single & & \\
Divorced & & \\
\hline
\end{tabular}

Table 1:- This table show that majority of participants age (51 and above) were (74.3\%), female were (91.7\%) and, married $(86.2 \%)$.

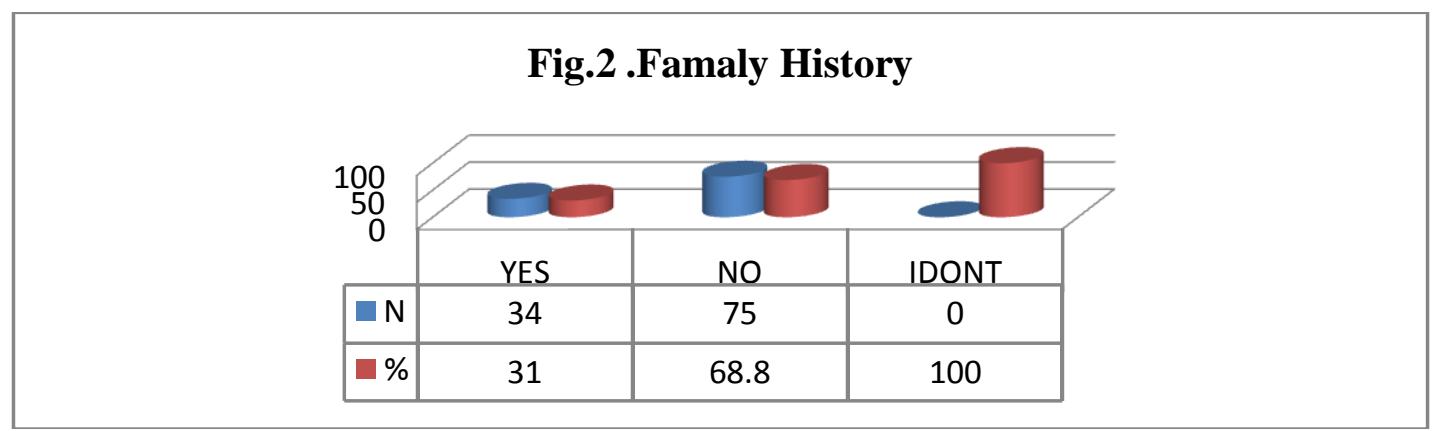

Fig 2:- This fig show that most of participants (68.8\%) no family history regard osteoporosis.

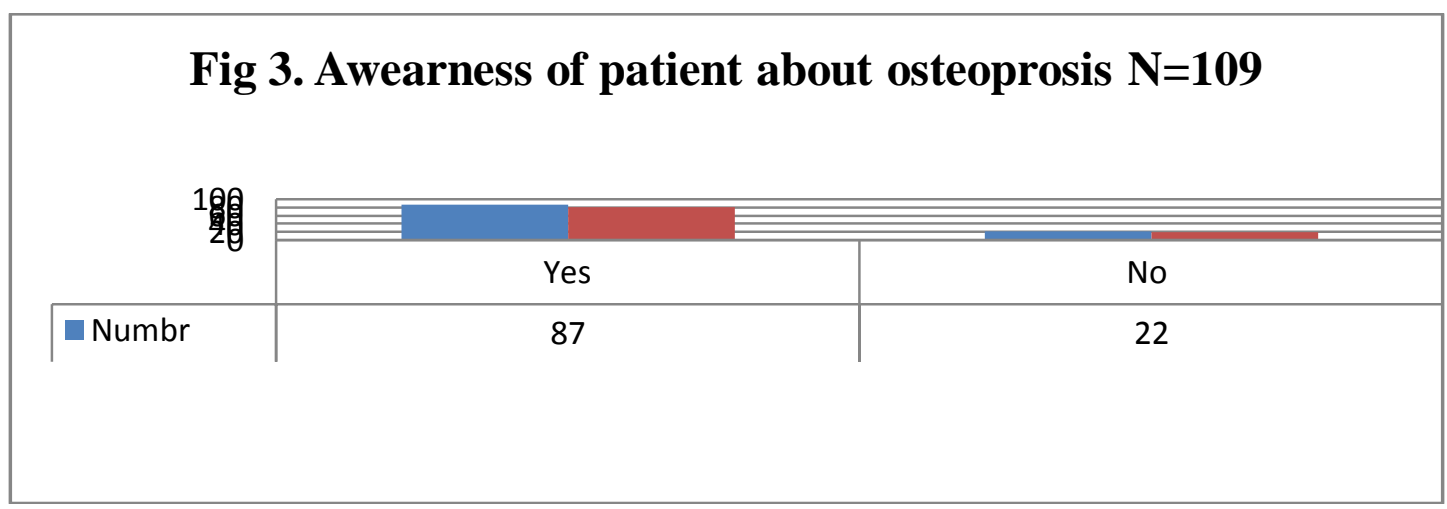

Fig 3:- This fig showed that (79.8\%) of participants a wear about osteoporosis. 
Table 2:- Patient knowledge regard risk factors of osteoporosis. ( $\mathbf{N = 1 0 9 )}$

\begin{tabular}{|c|c|c|}
\hline Risk factors of osteoporosis & Number & $\%$ \\
\hline \multicolumn{3}{|l|}{ Age } \\
\hline Yes & 95 & 86.2 \\
\hline No & 15 & 13.8 \\
\hline \multicolumn{3}{|l|}{ Medication } \\
\hline Yes & 25 & 22.9 \\
\hline No & 84 & 77.1 \\
\hline \multicolumn{3}{|l|}{ Exercising } \\
\hline Yes & 57 & 52.3 \\
\hline No & 52 & 47.7 \\
\hline \multicolumn{3}{|l|}{ Diet containing Dairy products such as milk } \\
\hline Yes & 71 & 65.1 \\
\hline No & 38 & 34.9 \\
\hline \multicolumn{3}{|l|}{ Cigarettes smoking } \\
\hline Yes & 3 & 2.8 \\
\hline No & 106 & 97.2 \\
\hline \multicolumn{3}{|l|}{ Dietary supplements such as calcium } \\
\hline Yes & 50 & 45.9 \\
\hline No & 59 & 54.1 \\
\hline
\end{tabular}

Table (2): This table represent age is the most risk factors, followed by diet contain calcium and exercising $(86.2 \%, 65.1 \%$, and $52.3 \%$, respectively)

Fig 4:- Participants Knowledge about BMD is the best test for osteoporosis. $(\mathbf{N}=\mathbf{1 0 9})$

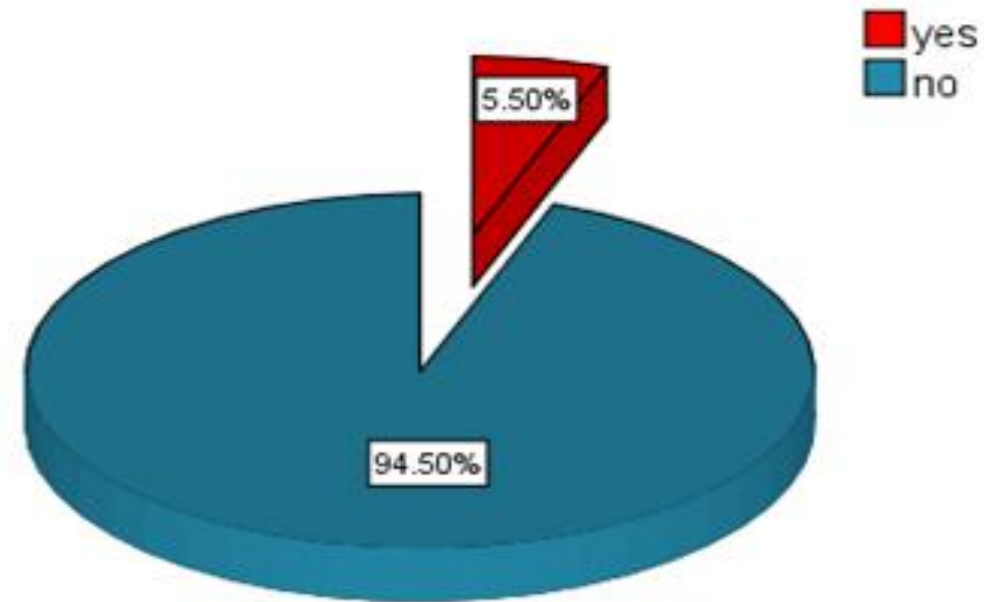

Fig 4:- Shows that $(94.5 \%)$ of participants have lack of knowledge about BMD is the best test for osteoporosis.

Table 3:- Attitude and practice regard osteoporosis among participant. ( $\mathbf{N}=\mathbf{1 0 9})$

\begin{tabular}{|c|c|c|}
\hline Variable & No & $\%$ \\
\hline $\begin{array}{l}\text { You do Exercise daily: } \\
\text { Yes } \\
\text { No }\end{array}$ & $\begin{array}{l}57 \\
52\end{array}$ & $\begin{array}{l}(52.3 \%) \\
(47.7 \%)\end{array}$ \\
\hline $\begin{array}{l}\text { Duration of exercise: } \\
10-30 \text { minutes a day } \\
30 \text { minutes-one hour a day } \\
\text { Once a week } \\
\text { No specific time }\end{array}$ & $\begin{array}{c}22 \\
3 \\
6 \\
26\end{array}$ & $\begin{array}{l}(20.2 \%) \\
(2.8 \%) \\
(5.5 \%) \\
(23.9 \%)\end{array}$ \\
\hline Do you take fruits (vitamins) daily: & & \\
\hline
\end{tabular}




\begin{tabular}{|l|c|c|}
\hline Enough amount & 21 & $(19.3)$ \\
Small amount & 62 & $(56.9 \%)$ \\
Unknown amount & 26 & $(23.9 \%)$ \\
\hline Diet containing dairy products such as milk: & & $(65.1 \%)$ \\
Yes & 71 & $(34.9 \%)$ \\
No & 38 & $(45.9 \%)$ \\
\hline Do you take calcium dietary supplements daily: & 50 & $(54.1 \%)$ \\
Yes & 59 & $(2.8 \%)$ \\
No & & $(97.2 \%)$ \\
\hline Cigarettes smoking: & 3 & \\
Yes & 106 & \\
No & & \\
\hline
\end{tabular}

Table 4:- Showed knowledge, attitude and practices among patient with osteoporosis. ( $\mathbf{N}=\mathbf{2 5})$

\begin{tabular}{|l|c|c|}
\hline Variables & Yes & NO \\
\hline Family history & $7(28 \%)$ & $18(72 \%)$ \\
\hline Exercise & $8(32 \%)$ & $17(68 \%)$ \\
\hline Smoking & $1(4 \%)$ & $24(96 \%)$ \\
\hline Diet containing Dairy products such as milk & $13(52 \%)$ & $12(48 \%)$ \\
\hline Calcium Supplement & $9(36 \%)$ & $16(64 \%)$ \\
\hline
\end{tabular}

Table 4:- This table shows that all patient with osteoporotic haven't knowledge and attitude about osteoporosis except diet contain dairy product such as milk (52\%).

Table 5:-Showed Knowledge about risk factors among osteoporotic patients.(N=25)

\begin{tabular}{|c|c|c|}
\hline Knowledge & $\begin{array}{l}\text { Yes } \\
\text { Ns }\end{array}$ & No \\
\hline Knowledge about osteoporosis & $18(72 \%)$ & $7(28 \%)$ \\
\hline Knowledge about BMD test & $0(0 \%)$ & $25(100 \%)$ \\
\hline Knowledge about steroids medication & $2(8 \%)$ & $23(92 \%)$ \\
\hline Knowledge that older people are more affected by osteoporosis & $20(80 \%)$ & $5(20 \%)$ \\
\hline
\end{tabular}

Table 5:- This table shows that most of participants have knowledge regard older people are more affected by osteoporosis $80 \%, 72$ have good knowledge about osteoporosis

Table 6:- Correlation between age \& BMD test result among study sample. (N=109)

\begin{tabular}{|c|c|c|c|c|c|c|}
\hline \multirow[b]{2}{*}{ Variable } & \multicolumn{3}{|c|}{ BMD test result } & \multirow[b]{2}{*}{ Total } & \multirow[b]{2}{*}{$X_{2}$} & \multirow[b]{2}{*}{$\begin{array}{c}\text { P. } \\
\text { value }\end{array}$} \\
\hline & Osteoporosis & Osteopenia & Normal & & & \\
\hline $\begin{array}{c}\text { Age } \\
21-30\end{array}$ & 0 & $2(1.83 \%)$ & $2(1.83 \%)$ & $4(3.66 \%)$ & $14.715^{\mathrm{a}}$ & 0.023 \\
\hline $31-40$ & 0 & $3(2.75 \%)$ & $8(7.33 \%)$ & $11(10.09 \%)$ & & \\
\hline $41-50$ & $3(2.75 \%)$ & $7(6.42 \%)$ & $3(2.75 \%)$ & $13(11.92 \%)$ & & \\
\hline 51-and above & $22(20.18 \%)$ & $41(37.61 \%)$ & $18(16.51 \%)$ & $81(74.31 \%)$ & & \\
\hline Total & $25(22.93 \%)$ & $53(48.62 \%)$ & $31(28.44 \%)$ & $109(100 \%)$ & & \\
\hline
\end{tabular}

Table 6;- Showed significant correlation between age \& BMD test result among study sample ( $\mathrm{P}=0.023)(\mathrm{N}=109)$. Most affected age group with Osteopenia (37.61\%) and osteoporosis (20.18\%) was (51years and above) and the least affected was (21-30 years).

\section{Discussion:-}

This study aimed to assess knowledge and attitude of osteoporosis among population have been referred for BMD ( Bone Mass Density) screening test in KAASH ( King Abdul Aziz Specialist Hospital) and KFH ( King Faisal Hospital ),Taif city in the period from January to April 2016. In this study 109 patient were examined by BMD, from them there were $(22.9 \%)$ have had osteoporosis while (48.6\%) have had osteopenia, as in fig(1). While in a study by (IJRMS 2014) BMD was measured in 100 Saudi women in the age group (40-75) years using DEXA scans to find out the prevalence of 
osteoporosis, results showed that $58 \%$ of the Saudi women had low BMD, (18\%) had osteoporosis and (40\%) had osteopenia.

Age groups in this study ranged from (21-79) year, age group (21-30y) represented (3.7\%),(31-40y) represented $(10.1 \%),(41-50 y)$ represented $(11.9 \%)$ and (51y and above) represented $(73.3 \%)$, from the 25 osteoporotic patient 22 of them were (51-and above) representing (20\%) so the most effected age group in this study was (51 and above),we found significant correlation between age \& BMD test result among study sample $(\mathrm{P}=0.023)(\mathrm{N}=109)$, as in table (1 and 6). Our result confirmed by (Sadat-Ali, et al 2012) who reported, epidemiological analysis showed that (34\%) of Saudi women, and $(30.7 \%)$ of men, (50-79) years of age are osteoporotic. (WHO 2013) reported increased life expectancy in KSA increasing from (45-67) years in 1960 to (75.7) years in 2013. In other study by (EMHJ 2009) reported prevalence of vertebral fractures in women over the age of 50 years was (20.3\%). In 2014, the National Osteoporosis Foundation estimated that a total of 54 million adults aged 50 and older in USA are affected by osteoporosis and low bone mass (Wright, et al.2014) . In Europe, in 2010 approximately 22 million women and 5.5 million men aged between 50 and 84 years are estimated to have osteoporosis.

In Egypt, based on different studies, it has been calculated that (53.9\%) of postmenopausal women have osteopenia and (28.4\%) haveOsteoporosis. On the other hand,(26\% )of men have osteopenia and (21.9\% )have osteoporosis. (Taha, 2011. Salem et al.,2000) reported that (16.7\%) of 1190 Egyptian menopausal females had lumbar Osteoporosis (Salem et al., 2000).

Regarding family history in this study (31.2\%) of the study sample have had positive family history ,while (68.8\%) haven't, from the 25 patient affected by osteoporosis only 7(28\%) had, as shown in fig(2). In study by (Prentice A, 2001) reported indeed, heritability studies have indicated that (60-70\%) of the variation in BMD within a population has a genetic origin. In other study by (Sedlak et al., 1998) they ending that women with a family history of osteoporosis felt more susceptible to developing osteoporosis than those who do not have a family history of osteoporosis, as women with a family history of osteoporosis have almost double the risk of developing osteoporosis.

In this study knowledge about that BMD is the best test to diagnose osteoporosis only (5.5\%) know that, as in fig(4).Patient awareness about osteoporosis, (79.82\%) from this study sample had good knowledge about osteoporosis, as in fig (3), from 25 osteoporotic patient 18(72\%) of them know the meaning of osteoporosis but all the 25 patient don't know BMD test, as in table (5).(Yosria E , 2014), reported that only (36.6\%) of participants had known the meaning of osteoporosis, the same results were obtained among the Turkish women by (Gemalmas and Oge.2008) and also among Taiwani young adult women by (Chang SF,2006). On the other hand higher proportions were obtained by (Alexandraki et al,2007 and Yeab et al,2010), who conducted their studies in Malaysia and Greece respectively. In other study by (Gemalmas and Oge,2008) only (44.9\%) of women defined osteoporosis correctly this proportion is low compared with another Turkish study that found (90\%) (Ungan et al 2001), and it may be related to lower educational level of rural sample.(Burke-Doe, et al.2008) reported despite the encouraging finding that those who had more knowledgeregarding osteoporosis also had improved bone health behaviors, (64\%) of the participants received scores below $(50 \%)$ on the osteoporosis knowledge assessment tool. Knowledge about the effect of using steroids medication in affecting bone health $(22.9 \%)$ told that they know and $(77 \%)$ told thatno. Corticosteroid induced osteoporosis is the most common form of secondary osteoporosis, causing earlier fractures in approximately $30 \%$ of individuals who use these drugs for an over age of 5 years $(\mathbf{N O F}, 1998) .(52.3 \%)$ of this study sample told that they do exercise daily , while $(47.7 \%)$ told that no. Regarding duration of exercise among study sample there were $(20.2 \%)$ exercise for (10-30 minuet a day) , (2.8\%) for (30 minuet-1hour a day), while (5.5\%) (once a week) and (23.9\%) they don't know the duration of their exercise from the 25 patient diagnosed with osteoporosis only 8 (32\%) exercise, as in table (2) .(Oommen , et al,2014) reported in study done in Saudi Arabia among 100 female patients screened for Vitamin D deficiency, (82\%) of the patients had Vitamin D deficiency, and among patients who have vitamin D deficiency Only 7 patients were doing some form of exercise of which 6 had normal BMD while 1 had osteopenia. Also (Stewart et al.2005) showed that exercise may preserve or increase BMD while reducing fatness. The most extensive evidence from human studies supporting the effect of exercise on bone mass has been obtained from studies of unilateral loading, as in tennis players, where the dominant arm has thicker cortices and up to (22\%) higher BMD than the non-dominant arm (Bass, et al.2002).

Regarding the role of exercise on bone physiology, $(88.3 \%)$ of the participants knew the fact that high-impact exercise in the form of weight training improves bone health, about $86.5 \%$ of the studied women knew that walking had an essential role in bone health, this suggests that most of women understand that walking has a beneficial effect on bone density 
similar to that of high impact exercise, in addition to, it's obvious cardiovascular benefits (Bonaiuti et al 2002,Yamazaki, 2004). Hence, on planning health education programs for prevention of osteoporosis , the health education messages should emphasize on the age period through which bone growth takes place, the different risk factors of osteoporosis, and preventive measures (Werner ,2005, Riaz,et al ,2008, , Malak et al 2015) .In this study according to amount of fruits (vitamins) intake by the sample only (19.3\%) said that they take a good amount of fruits daily. while $(56.9 \%)$ they don't take their needs from fruits daily and ( $23.9 \%)$ they don't know the amount ,as in table (3). Low intakes of vitamin B6 and other B-vitamins associated with low bone mineral content (BMC) and hip fracture. (New, et al. 2000, Tucker, et al. 1999) Stated that higher BMD has been associated with a higher dietary potassium intake, along with other nutrients associated with fruits and vegetable intake. In addition to supplying specific nutrients that may promote bone health, fruits and vegetables promote an alkaline environment by reducing the potential renal acid load and net endogenous acid production ( Resmer, et al. 1995).

Regarding diet containing dairy products such as milk among study sample $(65.1 \%)$ answered that they drink milk daily and $(45.9 \%)$ of study sample were using calcium supplements ,among osteoporotic patient (13) patient representing $(52 \%)$ answered that they drink milk daily and none of them use calcium supplement representing (100\%), as in tables (3and 4). The study done by (Warensjo, et al,2011) suggested that dietary calcium intake below approximately $700 \mathrm{mg}$ per day in women were associated with an increased risk of hip fracture, any fracture and osteoporosis. In a study by (Tai et al. 2015) included 59 eligible randomized controlled trials of dietary sources of calcium or calcium supplements in older adults (aged >50) to determine whether increasing intake from dietary sources has acts on BMD the results showed that ,Increasing calcium intake from dietary sources increased BMD by ( 0.6-1.0\%) at the total hip and total body at one year and by $(0.7-1.8 \%)$ at these sites and the lumbar spine and femoral neck at two years , calcium supplements increased BMD by (0.7-1.8\%) at all five skeletal sites. (El-Tawab et al 2015) reported that there was also a marked lack of knowledge among studied women regarding the proper amount of milk that should be given to children as well as postmenopausal women in order to provide the daily requirements of calcium (identified only by $(56.8 \%$ and $45.9 \%$ respectively). In this study regarding cigarettes smoking only $(2.8 \%)$ of the sample were smokers, only 1osteoporotic patient smoke representing $(4 \%)$,as in tables $(3,4)$. Many studies have provided evidence that smoking affects the balance of the naturally occurring processes of bone resorption and bone formation, resulting in low BMD. (Szulc et al,2002 and Vogel et al,1997) reported that exposure to smokeless tobacco extracts reportedly inhibits osteoblast metabolism. (Henderson et al,1995). In study by (Syed Sohail,2015) demonstrates a strong association of tobacco, chewed or smoked with osteoporosis, smokers were found to be (3.45) (CI-1.493-8.695) times more prone to develop osteoporosis at an early age compared to controls, it has been have found that BMD is decreased in smokers as from our data out of total number $(n=211)$ of cigarette smokers, $n=26(12 \%)$ were osteoporotic , majority of them were smoking since last +5 years and were consuming more than $(+10)$ cigarettes per day.

\section{Conclusion:-}

This study confirms that osteoporosis is a great health issue in Taif city, Saudi Arabia. The most reliable method for diagnosing osteoporosis is BMD test performed by DEXA machine. A significant correlation was found between age and $\mathrm{BMD}$ test $(\mathrm{P}=0.023)$, most affected age group with osteoporosis was (51 and above) with (74\%). knowledge of osteoporosis among study sample was moderate as regards its risk factors.

\section{Recommendations:-}

Awareness level should be elevated among Taif city community to prevent further growth of osteoporosis. Another study with large sample must be conducted in Taif region.

\section{Acknowledgment:-}

The authors thanks King Abdul Aziz Specialist Hospital (KAASH) and King Faisal Hospital ,Taif city - Saudi Arabia for their cooperative in data collection, also thanks extended to Dr. Magda Ahmed Mohammed Mansour and all book authors and sources from where the data discussed and reviewed.

\section{References:-}

1. Alexandraki KI, Syrion V, Ziakas NV, Piperi E, Kavoulaki I, Korres E,(2007). The knowledge of osteoporosis risk factors in a Greek female population, Maturitas. 59(1), 38-45.

2. Bass SL, Saxon L, Daly RM, Turner CH, Robling AG, Seeman E, Stuckey S. ,(2002). The effect of mechanical loading on the size and shape of bone in pre-, peri-, and post pubertal girls: a study in tennis players. J Bone Miner Res; 17 (12): 2274-2280. 
3. Bener A, Hammoudeh M, Zirie M (2007). Prevalence and predictors of osteoporosis and the impact of life style factors on bone mineral density, APLAR Journal of Rheumatology, 10: 227-233.

4. Bonaiuti D, Shea B, Iovine R, Negrini S, Robinson V, Kemper HC, et al (2002,)Exercise for preventing and treating osteoporosis in postmenopausal women. Cochrane Database Syst Rev (3): 333.

5. Burke-Doe A, Hudson A, Werth H, (2008) University of St. Augustine for Health Sciences at San Diego, Knowledge of osteoporosis risk factors and prevalence of risk factors for osteoporosis. Journal of Geriatric Physical Therapy , 1117.

6. Chang SF(2006). "A cross-sectional survey of calcium intake in relation to knowledge of osteoporosis and beliefs in young adult women." Int. J. Nur. Practice. 12: 21-27.

7. Damodsaran P, Subramanian R, Omar SZ, Nadkarni P, Paramsothy M., (2000).Profile of a menopause clinic in an urban population in Malaysia "Singapore Med J.; 41(9): 431-5.

8. El-Dessouki MI (1999) Osteoporosis in post-menopausal Saudi women using dual X-ray bone densitometry. Saudi Med J 20(4): 283-286.

9. Eastern Mediterranean Health Journal,15 (5).2009;6.

10. Ego Seeman and John A Eisman. Med J Aust 2004; 180 (6): 298-303.

11. El-Tawab SS et al. Knowledge of osteoporosis among women in Alexandria (Egypt): A community based survey, The Egyptian Rheumatologist 2015.

12. Genant HK, Engelk K..,(1999). Non-invasive assessment of the bone mineral and structure. State of the art. J Bone Miner Res; 11, 707-730.

13. Gemalmas and Oge A.,.(2008). Knowledge and awareness about osteoporosis and its related factors among rural Turkish women. Clin. Rheumatol.;27(6): 723-8.

14. Health Research Council (HRC) of New Zealand www.hrc.govt.nz 2004.

15. Henderson J.S, Johnson R.B.L,(1995);Department of Periodontics, University of Mississippi Medical Center, Jackson, MS 39216-4505, U.S.A The effects of smokeless tobacco extract on bone nodule formation and mineralization by chick osteoblasts in vitro. Arch Oral Biol40 : 615- 21 [PubMed].

16. International Journal of Research in Medical Sciences | January-March 2014;1.

17. Johnell $\mathrm{O}$ and Kanis JA (2006). An estimate of the worldwide prevalence and disability associated with osteoporotic fractures. Osteoporosis Int 17:1726.

18. Kanis JA on behalf of the World Health Organization Scientific Group (2007). Assessment of osteoporosis at the primary health care level. Technical Report.World Health 35-Organization Collaborating Center for Metabolic Bone Diseases. University of Sheffield, UK ; 2007.

19. Karimi W (2011) Preventing osteoporosis in menopause- A Literature Review, Published Bachelor's Thesis in General Nursing, Turku University Of Applied Sciences; 4-6.

20. Khosla S, Amin S, Orwoll E. (2008) Osteoporosis in men. Endocr Rev; 29: 441-64.

21. Kustal YG ,Atalay A, Aslan S ,Basaran A ,Cnturk F, Cindas A, et al .(2005). Awareness of osteoporotic patients. Osteoporosis Int; 16, 128-33

22. Leslie WD, Morin SN (2014). Osteoporosis epidemiology 2013: Implications for diagnosis, risk assessment and treatment. Curr Opin Rheumatol. 26(4), 440-6.

23. Linwdsay R and Cosman F:,(2001;): “Osteoporosis” in Harrison's Principles of Internal Medicine 15th Edition, McGraw-Hill, 2226:2237.

24. Maalouf G, Gannagé-Yared MH, Ezzedine J, et al:: (2007)Lebanese osteoporosis prevention society, Shariati hospital, Iran. Middle East and North Africa consensus on osteoporosis. J Musculoskeletal Neuronal Interact; 7:131143.[PubMed].

25. Maalouf G, Wehbe J, Nehme A, Moucharafieh R, Gannage -Yared MH, Chidiac RM, Yaghi Y (2006). Characteristics of hip fracture in Lebanese population. OsteoporosInt 17:S170.

26. Malak MZ, Toama ZT. (2015). The effect of osteoporosis health education program based on health belief model on knowledge and health beliefs towards osteoporosis.

27. National Osteoporosis Foundation, National Osteoporosis Report. 1998.

28. Mohy Taha , (2011) Prevalence of osteoporosis in Middle East systemic literature review, 10th ECOO, 4.

29. New SA, Robins SP, Campbell MK, et al. (2000). Dietary influences on bone mass and bone metabolism: further evidence of a positive link between fruit and vegetable intake and bone health. American Journal of Clinical Nutrition; 71: 142-51.

30. Osteoporosis Australia http://www.osteoporosis.org.au 2004.

31. Oommen A, Hassan I, Allahrakhyo S, et al, (2014).Relationship between body mass index and bone mineral density in Saudi women above 40 years with vitamin D deficiency Science Journal of Public Health; 2(6): 601-604.

32. Prentice A (2001)., Diet, nutrition and the prevention of osteoporosis. Public Health Nutrition: 7(1A), $227-243$.

33. Rasy NF, Chan JK, Thamer M, Melton LJ. (1997).Medical expenditures for the treatment of osteoporotic fractures in the United States in 1995: Report from the National Osteoporosis Foundation. J Bone Miner Res; 12:24-35. 
34. Resmer T, Manz F. (1995).Potential renal acid load of foods and its influence on urine pH. Journal of the American Dietetic Association; 95:791-2.

35. Riaz M, Abid N, Patel M, Tariq M, Khan MS, Zuberi L.(2008). Knowledge about osteoporosis among healthy women attending a tertiary care hospital. J Pak Med Assoc;58(4): 190-4.

36. Rouzi AA, Al Sibiani SA, Al Senani NS, Radaddi RM, Aradawi MS: , (2012).Independent predictors of all osteoporosis related fractures among healthy Saudi postmenopausal women :the CEOR study. Bone; 50: 713722.[PubMed].

37. Sadat-Ali M, Al-Habdan IM, Al-Turki HA, Azam MQ. (2012).An epidemiological analysis of the incidence of osteoporosis and osteoporosis related fractures among the Saudi Arabian population. Ann Saudi Med , 3: 637-641.

38. Sadat-Ali M et al.(2004).Bone mineral density among postmenopausal Saudi women. Saudi medical journal, 2004, 25:1623-5.

39. Sadat-Ali M, Al-Habdan I, Marwah S. (1996).Bone mineral density measurement of distal radius in Saudi Arabian females. Annals of Saudi medicine, 16:414-6.

40. Sambrook PN, Seeman E, Phillips SR and Ebeling PR (2002) Preventing osteoporosis: outcomes of the Australian Fracture Prevention Summit. Med J Austp:176.

41. Salem D, Tattawi S, Ebrashi H. (2000).Evaluation of osteoporosis among males and females in clinical practices bone densitometry. Med J Cairo Univ;68:89-92.

42. Saw SM, Hong CY, Lee J ,Wong ML, Chan MF, Cheng A, et al . (2003).Awareness and health beliefs of women towards osteoporosis. osteoporosis Int;14:595-601.

43. Sedlak CA, Doheny MO, Jones SL. (1998) Osteoporosis prevention in young women. Orthop Nurs. MayJun;17(3):53-60.

44. Stewart KJ, Bacher AC, et al, (2005). "Exercise effects on bone mineral density relationship to changes in fitness and fatness", Am J Prev Med. 2005; 28(5): 453-460.

45. Syed Sohail Abbas, Saeeda Baig et al., (2015).Osteoporosis in males and its association with tobacco; smokers and chewers 2015;15-18.

46. Szulc P, Garnero P, Claustrat B, Marchand F, Duboeuf F, Delmas PD.(2002) Increased bone resorption in moderate smokers with low body weight: the Minos study. J Clin Endocrinol Metab; 87(2):666-74.

47. Taha M. (2011).Prevalence of osteoporosis in Middle East systemic literature review. In: Proceedings of the 10th ECOO; 4: 14-16.

48. Tai V, Leung W, Grey A, Ian R, Mark J . Bolland ,(2015) Calcium intake and bone mineral density: systematic review and meta-Analysis; 1 .

49. The Middle East \& Africa Regional Audit:(2011): Epidemiology, costs \& burden of osteoporosis in. International Osteoporosis Foundation.

50. Tucker KL, Hannan MT, Chen H, Cupples LA, Wilson PW, Kiel DP.(1999): Potassium, magnesium, and fruit and vegetable intakes are associated with greater bone mineral density in elderly men and women. American Journal of Clinical Nutrition; 69: 727-36.

51. Ungan M ,Tumer M (2001) Turkish women's knowledge of osteoporosis. Fam Pract 2001;18:199-203.

52. Vogel JM, Davis JW, Nomura A, Wasnich RD, Ross PD.(1997) The effects of smoking on bone mass and the rates of bone loss among elderly Japanese-American men. J Bone Miner Res; 12(9): 1495 -01.

53. Wellness works Magazine . A part of ISU Employee Wellness Program 2008;1.

54. Warensjo E, Byberg L, Melhus H, Gedeborg R, Mallmin H, Wolk A, et al. (2011).Dietary calcium intake and risk of fracture and osteoporosis: prospective longitudinal cohort study. BMJ; 342:1473.

55. Werner P. (2005).Knowledge about osteoporosis: assessment, correlates and outcomes. Osteoporosis Int; 16 :115-27.

56. World Health Organization. WHO (2004).Scientific group on the assessment of osteoporosis at primary health care level. May.

57. World Health Organization. Saudi Arabia Health Profile 2013. Geneva (CH): WHO; 2013;1 .

58. Wright NC, Looker AC, Saag KG, Curtis JR, Delzell ES, Randall S, et al. (2014); The recent prevalence of osteoporosis and low bone mass in the United States based on bone mineral density at the femoral neck or lumbar spine. J Bone Miner Res 29(11): 2520-6.

59. Yamazaki S, Ichimura S, Iwamoto J, Takeda T, Toyama Y. (2004).Effect of walking exercise on bone metabolism in postmenopausal women with osteopenia/osteoporosis. J Bone Miner Metab; 22: 500-8.

60. Yeab SS, Goh EM, Das GE(2010). Knowledge about osteoporosis in Malaysia population. Asia Pac. J. Public Health. 22(2): 233-410.

61. Yosria EL-Sayed. (2014). Osteoporosis: knowledge practices and prevention among female adolescen in El-Minia, Egypt -Journal of Research in Nursing and Midwifery (JRNM); 66-72 . 